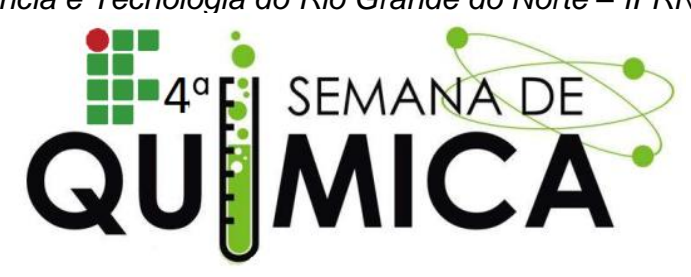

\title{
CONSTRUÇÃO DO BloQuímicosAD COMO PROPOSTA DE DIVULGAÇÃO DO ENSINO DE QUÍMICA
}

Autores: SOUZA, R. L. S. (IFRN); REINALDO, M. S. A. S.(EEPAD), FREITAS, P. V. J. (IFRN), BERTINI, L. M. (IFRN), ALVES, L. A.(IFRN), FERNANDES, P. R. N. (IFRN)

Palavras Chave: Mídias educacionais, Blogs, Recursos.

\section{INTRODUÇÃO}

As mídias educacionais surgem como um recurso oportuno com relação a sua utilização na educação devido sua extensa variedade de opções. O trabalho com blogs como ferramenta de apoio à aprendizagem e o seu manuseio de forma propicia, mostram-se de forma objetiva e positiva no âmbito educacional, visto que as mesmas podem facilitar o aprendizado e a fixação de conhecimentos. Diante deste contexto, a utilização de Blogs informativos surge como alternativa para uma aprendizagem mais significativa e atrativa por parte dos alunos.

Segundo Barro (2008, p. 10), "Os blogs podem ser utilizados com diversos propósitos educacionais em diversas disciplinas e diferentes níveis de escolaridade devido à sua característica de ferramenta flexível que não apresenta um limite de utilização". Sendo assim, para o ensino de Química, o uso dessa ferramenta inovadora, provoca situações de estímulo, despertem a curiosidade, a descoberta e o conhecimento em sala de aula (SANTOS, 2012).

Por ser uma ferramenta de fácil manuseio tanto em sua elaboração quanto a sua navegação por parte dos alunos diferentemente dos sites convencionais, o Blog surge como meio facilitador tanto para o Aluno quanto para o autor do mesmo, visto que este recurso não requer um alto nível de conhecimentos em informática para sua aplicação e desenvolvimento.

Conforme SOUZA (2013), os blogs de acordo com suas características, podem ser classificados segundo sua finalidade em: blogs de interação (e aqui estão os milhares de blogs sociais) e de aprendizado.

A opção do uso de blogs como ferramenta pedagógica, se dá ao fato de uma nova forma que possibilita e propicia os educandos e professores a utilizarem a internet de modo mais interativa, fazendo-se o uso textos selecionados prontos, abordagens de questões da atualidade, participando assim de uma construção coletiva e colaborativa do conhecimento (SOUZA, 2013).

Diante do exposto, foi criado um Blog como uma iniciativa desenvolvido pelos bolsistas do PIBID (Programa Institucional de Bolsa de Iniciação à Docência), cujo propósito principal era sanar as dúvidas relacionadas aos conhecimentos químicos que os estudantes encontravam em seus estudos cotidianos. 0 Blog serviria também como uma forma de divulgação do programa e sua influencia positiva no ensino aprendizado dos alunos.

\section{METODOLOGIA}

Como procedimento metodológico, teve como base inicial a metodologia de (SANTOS, 2012), no qual foi realizado um estudo teórico relacionado a blogs educacionais, e que teve como principal fonte de pesquisa dos mesmos, o Google Acadêmico, Portal Scielo e o Periódico CAPES. Em seguida, foi elaborado o blog com os conhecimentos específicos da área de Química, composto de textos, questões, curiosidades, química no cotidiano, entre outros. Recursos estes complementares para auxiliar $o$ aluno na 
aprendizagem e fixação dos conteúdos estudados em sala de aula.

O blog foi elaborado pelos bolsistas do PIBID, que fizeram sua divulgação na Escola Estadual Professor Antônio Dantas, na cidade de Apodi, Rio Grande do Norte. Além do conteúdo relacionado aos alunos, o Blog faz divulgações de trabalhos elaborados pelos bolsistas, dentre eles Jogos Lúdicos, aulas praticas realizadas com os alunos, e artigos apresentados em congressos.

\section{RESULTADOS E DISCUSSÕES}

O seguinte projeto tem como foco, abordar os conhecimentos de Química assim como a divulgação de trabalhos elaborados pelos bolsistas do PIBID com os Alunos da rede publica do ensino médio, na cidade de Apodi/RN, a fim de se obter um melhor desenvolvimento desses alunos preparando-os para a construção ativa de seu próprio conhecimento.

O blog BloQuímicosAD disponhe do seguinte endereço eletrônico para o acesso, $>$ http://blogquimicopibid.blogspot.com.br/<. A Figura a seguir apresenta prints das páginas do blog.

Figura 01: Recortes das páginas do BloQuímicosAD
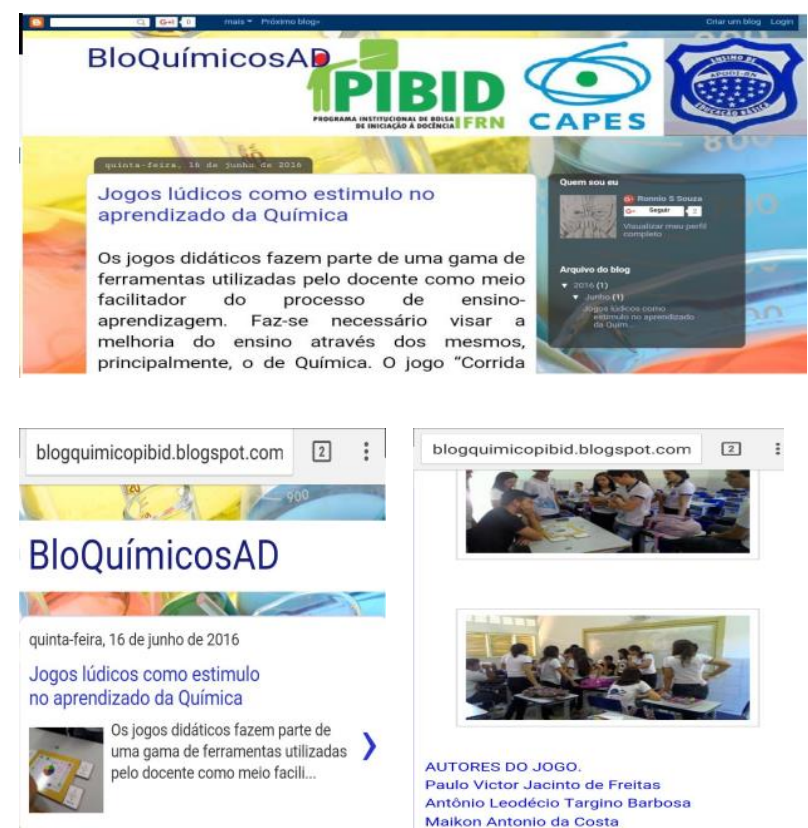

AUTORES DO JOGO.

AUTORES DO JOGO. Paulo Victor Jacinto de Freitas
Antônio Leodécio Targino Barbo
Maikon Antonio da Costa
A Química em geral assim como o seu ensino, tem grande papel diante a sociedade, por isso novas metodologias de repasse desse conteúdo tem sido estudada.

Segundo Santos $(2012$, p. 7) o professor precisa trabalhar com práticas pedagógicas que favoreçam a aprendizagem fora do espaço escolar, criando assim um ambiente virtual que oportunize a construção do conhecimento em qualquer ambiente.

O blog ainda está em fase inicial, sendo atualizado com as informações que se julga de interesse dos estudantes do ensino médio.

\section{CONCLUSÃO}

A utilização das mídias educacionais neste caso o blog, para abordagem do ensino de Química no intuito de melhorar e fixar os conhecimentos de sala de aula mostra-se oportuno diante das características abordado neste trabalho.

Os alunos se mostram interessados com a possibilidade de ter um blog que possa auxiliar no seu processo de aprendizagem.

\section{REFERÊNCIAS}

1 BARRO, Mario R. Blogs: Aplicação na Educação em Química. Universidade Luterana do Brasil (ULBRA), Canoas/RS, 21 de outubro de 2008.

2 SANTOS, Ranniery F. O uso de blogs como ferramenta de aprendizagem: a tecnologia aliada à disciplina de Química no Ensino Médio. VII CONNEPI, Palmas/Tocantins, 2012.

3 SOUZA, Carlos A. S. O Blog como Ferramenta de Aprendizagem no Ensino de Química. Universidade Federal do Ceará (UFC), Fortaleza/CE, 2013. 